\title{
Impact of Economic Policy Uncertainty on the Stability of Enterprises Embedded in a Global Value Chain
}

\author{
Huizheng Liu ${ }^{1}$, Jingyi Zhang ${ }^{1 *}$, Qi Han ${ }^{1}$, Wenshen Pan $^{1}$ and Muhammad \\ Afaq Haider Jafri ${ }^{1}$
}

\begin{abstract}
The world economic situation is unpredictable, and uncertain factors accompany each other. Economic policy uncertainty (EPU) has become the main factor affecting sustainable economic development and the stability of enterprises embedded in the global value chain (GVC). This paper uses the duration of embeddedness in the GVC to measure the stability of the embedded GVC and explores the impact of domestic and foreign EPU on the stability of Chinese enterprises embedded in the GVC. The results show that the stability of Chinese enterprises embedded in the GVC is low; domestic and international EPU reduces the stability of Chinese enterprises embedded in the GVC; and international EPU significantly reduces the stability of private enterprises, foreign invested enterprises and enterprises involved in import and export of intermediate goods embedded in the GVC, while domestic EPU significantly reduces the stability of state-owned enterprises, private enterprises, large, medium and small enterprises and enterprises involved in import and export of intermediate goods embedded in the GVC. In the influence mechanism, domestic EPU inhibits the innovation ability of enterprises and then affects the stability of enterprises embedded in the GVC.
\end{abstract}

JEL classification numbers: F620, F680

Keywords: Economic policy uncertainty, Global value chain, Stability, Duration.

${ }^{1}$ College of Economics and Management, Beijing University of Technology, Beijing 100124, China. 


\section{Introduction}

Since the outbreak of the financial crisis in 2008, the world economy has faced great challenges, and the macroeconomic policies of various countries have been constantly adjusted and interacted with each other. Moreover, there have been many "black swan incidents" worldwide, such as the Sino-US trade friction and COVID-19 pneumonia pandemic, which have caused economic policy uncertainty (EPU) to continue to increase and seriously affected the sustainable development of the world economy. EPU will increase the difficulty of enterprise decisionmaking, affect the macroeconomy and microenterprise behavior, and make the transnational production network that connects the economies of various countries face a serious impact (Handley and Limão,2017). Especially under the impact of the COVID-19 pneumonia pandemic, most industries participating in the global value chain (GVC) are facing insufficient demand and supply, which increases the risk of GVC breaks (Yagi and Managi,2021), and it is not conducive to the stability of enterprises embedded in the GVC, affecting the sustainable development of internet trade. Therefore, in the current increasingly complex and severe international political and economic situation, maintaining the stability of enterprises participating in the GVC has become an important issue that urgently needs to be solved.

\section{Literature Review}

With regard to the research on EPU, from the macroeconomic perspective, there are different states of EPU in different periods (Pastor and Veronesi,2012). Uncertainty has produced substantial macroeconomic effects through sticky prices, labor search friction, financial friction and other channels. EPU will have a negative impact on GDP, unemployment, total output, income level and resident consumption. Policy uncertainty can be a source of economic fluctuation (Basu and Bundick,2017; Leduc and Liu,2016; Alfaro et al.,2018; Haroon,2018) and increase the volatility of commodity prices (Bakas and Triantafyllou,2018). From a microeconomic perspective, an increase in policy uncertainty will restrain investment enthusiasm and reduce the financing of enterprises (Julio and Yook,2012; Gulen and Ion,2016; Caldara et al., 2020); due to the precautionary motives of enterprises, investment will be delayed, and cash holdings will be increased (Phan,2019). Trade policy uncertainty increases firm financial constraints and operational risk (Wang et al.,2021). An institutional environment with high EPU provides convenience for enterprises to engage in corporate fraud (Hou et al.,2021). During periods of national policy uncertainty, the innovation activities of enterprises are restrained (Bhattacharya et al.,2017).

Facing the uncertainty of policies, economic stability can be reflected in economic resilience, that is, the resilience of the economic system after being disturbed. Economic stability is reflected in the combination of economic fluctuation and economic growth, that is, the ability of a country's economy to restore its original growth state after facing external shocks (Martin and Sunley,2015). Stability can 
be studied in terms of duration. Most of the studies on the duration of international trade adopt survival analysis. In early research, continuous time series models are typically used (Besedes and Prusa,2006), while in later research, discrete-time Cloglog models, probit models and logit models are widely used to study the influencing factors of duration (Chen et al.,2017). Uncertainty inhibits the development and sustainability of trade, increases the potential trade costs of exporters, makes exporters have to give up overseas markets, reduces the optimal trade scale and worsens existing trade relations (Carballo et al.,2018; Greenland et al.,2018). The duration of international trade relations has negative time dependence. The longer the duration of trade relations is, the lower the hazard rate of trade relations failure (Esteve-Pérez et al.,2013). At present, the research on the duration of international trade focuses on the duration of import and export trade. Besedes and Prusa(2006) studied the duration of a country's import trade and the factors affecting it. Nitsch (2009) stated that the duration of a country's export trade is affected by exporter characteristics, product type and market structure. In the face of poor economic stability and uncertain factors having a great impact on the economy, improving the stability of enterprises embedded in GVCs has become a noteworthy topic. The occurrence of COVID-19 has weakened the ability of enterprises to be embedded in GVCs (Sun et al.,2021). However, there are few studies on the duration of GVC embedding. The research on GVC embedding is more focused on the degree of enterprises embedded in the GVC. Enterprise cost, technological progress and innovation, and financing constraints are the main factors affecting the degree of enterprises embedded in the GVC (Bridgman,2012; Humphrey and Schmitz,2002; Manova and Yu,2012). With the increase in EPU, transnational corporations will delay foreign investment, which will undoubtedly reduce the level of foreign capital flowing into the domestic market and inhibit the import of foreign intermediate products to reduce the proportion of the value-added rate of domestic export products (Nguyen et al.,2018). Enterprises are faced with problems such as financing constraints and credit discrimination, resulting in the reduction of enterprises embedded in the GVC. Furthermore, to avoid the legal and tariff risks that enterprises may face in the future, enterprises will reduce foreign direct investment. Banks will become cautious, resulting in a decrease in the bank loan amount or an increase in the loan interest rate, reducing the main source of enterprise investment funds and forcing enterprises to reduce the scale of investment, thus inhibiting the level of enterprise foreign direct investment (Christensen and Dib,2008). This scenario leads to a reduction in the technology spillover effect and is embedded in the GVC (Daniels and Ruhr,2014; Zheng et al.,2020).

The above literature lays the foundation for the writing of this paper. Under the division of the labor system of the GVC, with the intensification of economic policy uncertainty, the GVC is facing the problem of increasing chain breakage risk, and the stability embedded in the GVC directly affects the sustainable development of enterprises. Among the existing studies, more attention is given to the impact of EPU on enterprise investment behavior, while less attention is given to the stability 
of enterprises embedded in the GVC. Moreover, the research on stability focuses more on the duration of import and export trade, ignoring the importance of embedding the duration of GVC. Based on the above, the marginal contributions of this paper are as follows: (1) From the perspective of EPU, innovatively studying the influence and mechanism of EPU on the stability of Chinese enterprises embedded in the GVC, which enriches the relevant research of EPU and GVC; (2) Exploring the influence of different EPU on the stability of Chinese enterprises embedded in the GVC from domestic and international dimensions; (3) Based on the heterogeneity of enterprises, this paper analyzes the heterogeneity of the influence of economic policy uncertainty on the stability of enterprises participating in the GVC from the aspects of enterprise nature, enterprise scale, trade mode and embedding mode of GVC.

\section{Data and Methods}

\subsection{Stability of embedded in the GVC}

\subsubsection{Measurement of stability of embedded GVC}

In this paper, the duration of enterprise embedding $\mathrm{GVC}$ is used to reflect the stability of the enterprise embedding GVC. The duration of an enterprise embedding GVC is the time from the beginning of being embedded in the GVC to the exit from the GVC. If an enterprise embeds GVC in years $n$ to $m$ and does not embed GVC in years $(n-1)$ and $(m+1)$, the duration of the enterprise embedding GVC is $(m+1-n)$ years. However, this measurement method has the problems of "left censoring" and "right censoring". Left censoring means that the enterprise is embedded in the GVC at the beginning of the sample period, and the specific time of embedding cannot be determined. Therefore, in this paper, left censored enterprise data are eliminated. Right censoring means that the enterprise has not quit the GVC at the end of the sample period, so it is impossible to determine the time when the enterprise will quit the GVC. Referring to the method of Lv et al.(2017). Using the survival analysis method, a binary variable censor is constructed to address the right censoring problem: 0 represents the enterprise being embedded in the GVC, and 1 represents the enterprise exiting the GVC. For enterprises with right censoring, the censor variable is taken as 0 for every year. For enterprises with complete data (there is no left censoring or right censoring), the last year of being embedded in the GVC is recorded as 1 , and the other years are recorded as 0 . Moreover, enterprises may frequently enter and exit the international market, which leads to multiple duration periods of embedded GVC. Therefore, this paper considers only the first duration of enterprises.

How can it be determined whether an enterprise is embedded in the GVC? Foreign added value (FVA) in exports occurs through the import and re-export of intermediate products and brings added value to trading partner countries (Koopman et al.,2010). Hummels et al.(2001) first proposed the vertical specialization measurement framework to obtain the foreign added value rate (FVAR). Since then, most scholars use the FVAR in export of the enterprise to 
judge whether the enterprise is embedded in the GVC. If FVAR is not 0 , the enterprise was embedded in the GVC in that year. However, Upward et al.(2013) assumed that the FVA comes from the intermediate input of imports or indirect imports. Among the domestic raw materials used by enterprises, there is the possibility of containing foreign value-added shares (Koopman et al.,2012). Therefore, Lv et al.(2017) has improved this problem on the basis of predecessors, but this method still has shortcomings. According to the definition of the GVC provided by the United Nations Industrial Development Organization, the GVC involves not only intermediate products used to produce other goods and services but also other goods that do not need to be reprocessed and utilized. BEC divides international trade goods into three categories, namely intermediate goods, capital goods and consumer goods, all of which participate in the GVC network. However, the method of Lv et al.(2017) considers only enterprises that include the import and export of intermediate products and does not consider enterprises with capital goods or consumer goods that lack intermediate products. Therefore, to ensure comprehensive consideration, this paper further improves this problem and brings these three categories of products into the research scope. The enterprises participating in the GVC can be divided into two types: those involved in the import and export of intermediate products and those not involved in the import and export of intermediate products. If an enterprise has an added value rate of exporting abroad, the enterprise is involved in the import and export of intermediate products. If an enterprise has import and export data but does not have an export value-added rate, the enterprise does not process intermediate products. The specific calculation method of the export value-added rate is as follows: the former is enterprises that have FVAR and use FVAR to measure whether the enterprise is embedded in the GVC; the latter is enterprises that do not have FVAR and use import and export data to measure. The specific calculation method of FVAR is as follows:

$$
F V A R=\frac{V_{A F}}{X}=\frac{\left\{M_{A}^{p}+X^{o}\left[M_{A m}^{o} /\left(D+X^{o}\right)\right]\right\}+0.05\left\{M^{T}-M_{A}^{p}-M_{A m}^{o}\right\}}{X}
$$

where $\mathrm{O}$ refers to general trade, $\mathrm{P}$ refers to processing trade, and $\mathrm{M}, \mathrm{X}$ and $\mathrm{D}$ refer to the import, export and domestic sales of enterprises, respectively. $M^{T}$ is the intermediate input of enterprises, and $5 \%$ indicates the proportion of foreign added value that may exist in domestic intermediate input. In this paper, intermediate trader enterprises are selected, and the proportion of their cumulative imports to total imports $m^{i}$ is used to express the indirect imports of enterprises; $\left(1-m^{i}\right)$ is recorded as direct imports. $M_{A}^{p}$ and $M_{A m}^{o}$ are the actual processing trade import amount of enterprises and the intermediate input import amount of general trade, respectively.

$$
M_{A}^{p}=\sum_{i} \frac{M^{p}}{1-m^{i}}
$$




$$
M_{A m}^{o}=\sum_{i} \frac{M_{m}^{o}}{1-m^{i}}
$$

\subsubsection{Measurement results}

This paper measures the duration of Chinese enterprises embedded in the GVC. The results are shown in Table 1. The average duration of Chinese enterprises being embedded in the GVC is short, and the stability of participating in the GVC is weak. The average duration of Chinese enterprises being embedded in the GVC is 2.21 years, with $54.8 \%$ of enterprises lasting more than one year and only $4.12 \%$ of enterprises participating in the GVC more than five years. The duration and survival rate of enterprises embedded in the GVC decreased in turn from the eastern, western and central regions, which was related to the perfection of infrastructure construction, industrial supporting facilities and economic development in each region. Under different trade modes, the participation of processing trade enterprises in the GVC is the most stable, with an average duration of 2.45 years and the highest survival rate. The duration of general trade is the shortest, at 2.05 years. Compared with state-owned enterprises and private enterprises, foreignfunded enterprises have a long duration of embedment in the GVC, with an average of 2.78 years, which is mainly because foreign-funded enterprises often have more stable means of international integration. In addition, enterprises involved in intermediate products embedded in the GVC for a longer time have a higher survival rate.

Table 1: Stability of embedded GVC

\begin{tabular}{|c|c|c|c|c|c|c|}
\hline \multirow[t]{2}{*}{ Classification } & \multirow{2}{*}{$\begin{array}{c}\text { Average } \\
\text { duration } \\
\text { (years) }\end{array}$} & \multicolumn{3}{|c|}{$\begin{array}{c}\text { Survival rate estimated } \\
\text { by KM method (\%) }\end{array}$} & \multirow{2}{*}{$\begin{array}{c}\text { Number } \\
\text { of } \\
\text { duration } \\
\text { periods } \\
\text { (pieces) }\end{array}$} & \multirow[t]{2}{*}{$\begin{array}{c}\text { Number of } \\
\text { failures }\end{array}$} \\
\hline & & 1 & 3 & 5 & & \\
\hline Total & 2.21 & $54.80 \%$ & $20.30 \%$ & $4.12 \%$ & 79,535 & 45,394 \\
\hline Eastern & 2.24 & $55.50 \%$ & $21.13 \%$ & $4.36 \%$ & 70,522 & 39,767 \\
\hline Central Region & 1.96 & $48.44 \%$ & $13.61 \%$ & $2.04 \%$ & 5,526 & 3,441 \\
\hline Western & 2.01 & $49.67 \%$ & $15.03 \%$ & $2.75 \%$ & 3,487 & 2,930 \\
\hline General trade & 2.05 & $48.59 \%$ & $16.12 \%$ & $4.16 \%$ & 6,689 & 500 \\
\hline Processing trade & 2.45 & $60.24 \%$ & $26.26 \%$ & $6.08 \%$ & 11,291 & 509 \\
\hline Mixed trade & 2.19 & $54.69 \%$ & $19.59 \%$ & $3.75 \%$ & 61,913 & 34,385 \\
\hline State-owned enterprises & 2.29 & $56.63 \%$ & $19.94 \%$ & $6.35 \%$ & 1,780 & 1,368 \\
\hline Private enterprises & 1.99 & $49.39 \%$ & $14.23 \%$ & $2.47 \%$ & 57,366 & 35,284 \\
\hline Foreign-funded enterprises & 2.78 & $68.32 \%$ & $35.23 \%$ & $8.31 \%$ & 19,498 & 8,741 \\
\hline $\begin{array}{l}\text { Enterprises not involved in } \\
\text { intermediate products }\end{array}$ & 1.87 & $46.67 \%$ & $12.35 \%$ & $1.06 \%$ & 41,607 & 24,654 \\
\hline $\begin{array}{l}\text { Enterprises involved in } \\
\text { intermediate products }\end{array}$ & 2.59 & $63.63 \%$ & $29.10 \%$ & $7.49 \%$ & 37,928 & 20,740 \\
\hline
\end{tabular}




\subsection{Economic policy uncertainty}

\subsubsection{Measurement of EPU}

There are two main ways to measure EPU in the existing literature. The first is to take leader change as an indicator of EPU. A leader change leads to potential changes in national future economic policies and increases the expectation of EPU. Therefore, many studies use leader change to measure EPU (Alesina and Perotti,1996; Julio and Yook,2012). The second is to use the EPU index compiled by Baker et al.(2016) to measure the EPU of a country (region). According to the availability of data, this paper selects the second method to measure EPU, and the geometric average method is used to sum the EPU index with the original data as monthly and quarterly data into annual data. The specific algorithm is as follows:

$$
E P U_{t}=\frac{\sqrt[12]{E P U_{i}^{*} E P U_{i-1}^{*} * \ldots * E P U_{i-11}}}{100}
$$

where $E P U_{t}$ is the EPU index of year $t, E P U_{i}$ is the economic policy uncertainty number of month $i$ of year $t$, and $i$ has a value of 1-12.

\subsubsection{Measurement results}

This paper adopts the monthly EPU index compiled by Baker et al. and summarizes it into annual data by means of the geometric average. Figure 1 depicts the changing trend of the EPU index in China, the world and the three other countries from 2000 to 2007. The average value of global EPU is 76.9, with a standard deviation of 14.57, while the average value of China's EPU is 87.75, with a standard deviation of 26.8. Overall, the trends of the EPU index in China and the world are essentially the same, with the lowest value of 55.68 and the highest value of 129.16, with great fluctuations. China's EPU is higher than the global level. Compared with that of the other three countries, namely, the United States, Russia and Japan, the trend changes in EPU index in various countries are consistent, with the United States fluctuating the most, Japan fluctuating the least, and China having relatively large fluctuations. As shown in Figure 1, the EPU index for countries increased significantly in 2001. On the one hand, China had to adjust its economic policies before joining the WTO, which led to a relative reduction in the freedom of macrocontrol, an increase in the risks faced by the national macroeconomy, and an increase in EPU. On the other hand, in 2001, the bursting of the American internet bubble had a serious impact on the economic development of the United States, and the "9.11" terrorist attack in that year aggravated the economic recession of the United States and even the whole world. Countries issued corresponding economic policies, resulting in a sharp rise in the global EPU index. 


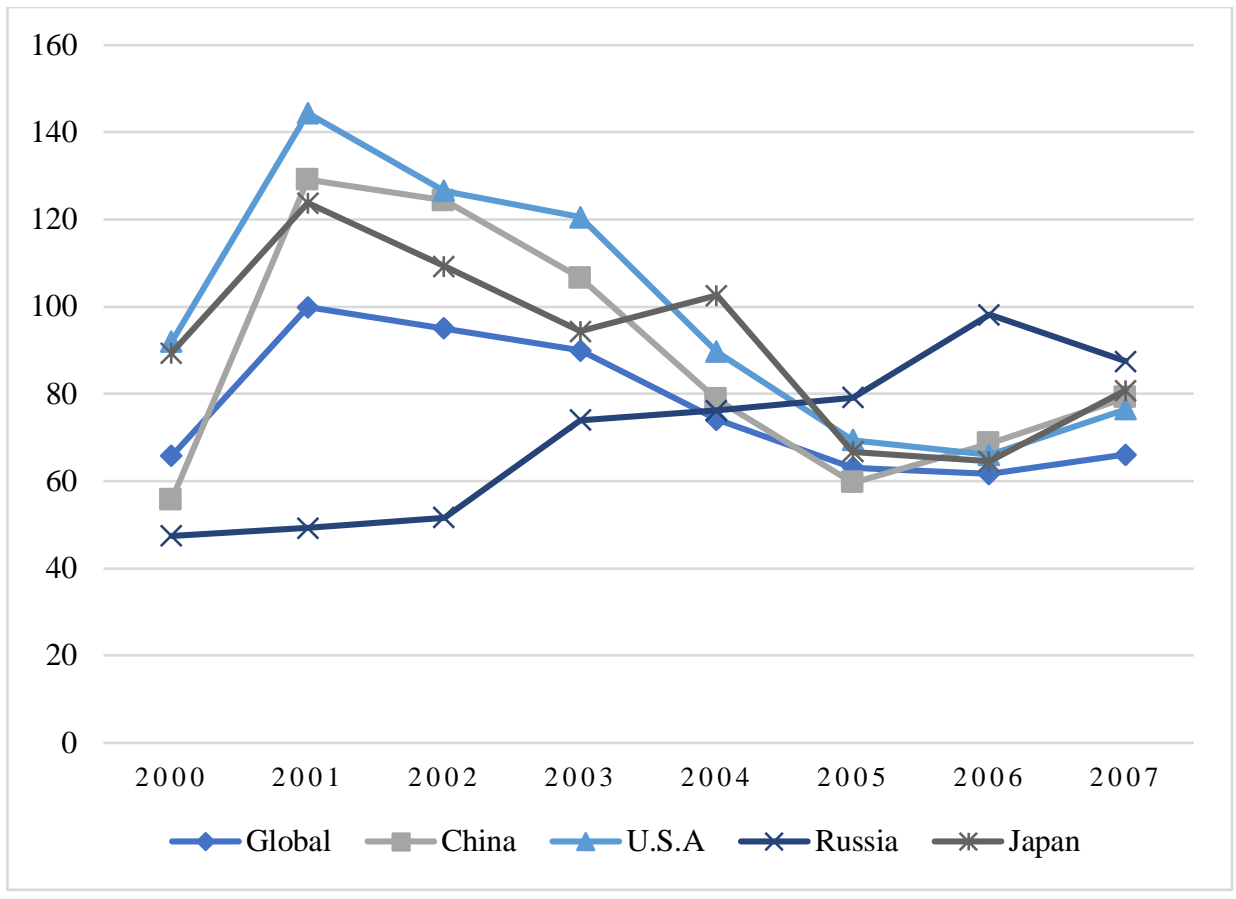

Figure 1: The index of EPU

Notes: The vertical axis is the EPU index, and the horizontal axis is the year

\subsection{Econometric model}

This paper uses Besedes and Prusa (2006) to construct a discrete-time Cloglog survival model to analyze the influence of EPU on the stability of enterprises embedded in the GVC:

$$
\begin{aligned}
& \operatorname{clog} \log \left(1-h_{i t}\right)=\alpha_{0}+\alpha_{1} * E P U G_{i t}+\gamma * X_{i j k t}+v_{t}+v_{j}+v_{k}+\varepsilon_{i j k t} \\
& \operatorname{clog} \log \left(1-h_{i t}\right)=\alpha_{2}+\alpha_{3} * E P U C_{i t}+\gamma * X_{i j k t}+v_{t}+v_{j}+v_{k}+\varepsilon_{i j k t}
\end{aligned}
$$

Equation (5) is a discrete-time cloglog survival model constructed using the survival analysis method to investigate the influence of international policy uncertainty on the stability of enterprises embedded in the value chain. Equation (6) examines the influence of domestic economic policy uncertainty on the stability of enterprises embedded in the value chain. $E P U G_{i t}$ and $E P U C_{i t}$ denote the uncertainty index of international and domestic economic policies corresponding to enterprise $i$ in year $t$, respectively. $X_{i j k t}$ represents control variables, and $i 、 j 、 k 、 t$ represent enterprises, industries, regions and years, respectively.

1. Financing constraints (finance): Financing constraints reflect the operation and development of enterprises, and EPU increases the difficulty of enterprise financing and affects enterprise behavior. Therefore, financing constraints are added as a 
control variable and measured by the ratio of enterprise interest expenses to sales. 2. Enterprise size (size): The larger the enterprise size is, the more stable the enterprise development. Size is measured as the logarithm of the number of employees.

3. Total factor productivity (tfp): This value is calculated via the OP method (Olley and Pakes, 1996).

4. Nature of enterprise (myfs): According to the previous analysis, different types of enterprises have different durations of being embedded in the GVC, so the nature of the enterprise is controlled in the form of virtual variables: state-owned enterprises equal to 1 , private enterprises equal to 2 and foreign-funded enterprises equal to 3 .

5. Trade mode (qyxz): According to the previous analysis, the embedded GVC stability of enterprises with different trade modes is different, so the trade mode of enterprises is controlled in the form of virtual variables: general trade enterprises equal to 1 , processing trade enterprises equal to 2 and mixed trade enterprises equal to 3 .

6. Enterprise age (age): The older an enterprise is, the more appropriate its production and operation mode is and the higher its development stability is. Age is measured by the current year minus the year of opening plus 1 .

7. Herfindahl index (HHI): The Herfindahl index reflects the market concentration of various industries and comprehensively reflects the differences in the number and relative scale of enterprises. This paper uses the proportion of enterprise sales to industry sales and then squares and sums industries.

$v_{t} 、 v_{j} 、 v_{k}$ represents the fixed effects of industry, region and year, and $\varepsilon_{i j k t}$ represents the random disturbance term.

In addition, $\quad h_{i t}=\operatorname{pr}\left(T_{i}<t+1 \mid T_{i} \geq t, x_{i t}\right)=1-\exp \left[-\exp \left(\varphi^{\prime} x_{i t}+u_{i}\right)\right]$ indicates the discrete-time risk rate. The larger the enterprise's $c \log \log \left(1-h_{i t}\right)$ is, the higher the probability of the enterprise withdrawing from the GVC, that is, the shorter the duration of the enterprise participating in the value chain. $u_{i}=\ln \left(v_{i}\right), v_{i}$ obeys a Gamma distribution. Binary variables are introduced and assigned to the dependent variable of the formula. Quitting the global value chain is defined as a failure event, which is recorded as 1 , and no failure event is recorded as 0 . In this paper, the dependent variable determines whether an enterprise participates in the GVC by measuring the participation degree of the value chain and combining it with import and export data; then, binary assignment is performed. If an enterprise participates in the GVC in that year, the assignment is 0 , and if it exits the GVC, the assignment is 1. Therefore, in the empirical process, a negative coefficient means that the enhancement of economic policy uncertainty will promote enterprises to reduce the probability of withdrawing from the GVC, which is conducive to the stability of enterprises participating in the GVC. 


\subsection{Data sources}

This paper makes use of the "China Industrial Enterprise Database" and "Customs Database" from 2000 to 2007 to match the two databases and measure the duration of enterprises embedded in the GVC and other related indicators. The "EPU Index" is the official data jointly released by Stanford University and the University of Chicago. The original data come from the website of policy uncertainty ${ }^{1}$ (http://www.policyuncertainty.com). After geometric averaging of monthly indicators, the annual data are calculated and matched with the enterprise data.

\section{Results and Discussion}

\subsection{Basic regression}

Using Equations (5) and (6), this paper conducts a basic regression analysis on the influence of international and domestic EPU on the stability of Chinese enterprises embedded in the GVC, and the regression results are shown in Table 2. The results show that both international and domestic EPU can increase the probability of enterprises exiting the GVC and reduce the stability of enterprises becoming embedded in the GVC. Among the control variables, financing constraints reduce the stability of enterprises embedding the GVC; the HHI coefficient is positive, that is, the larger the HHI index is, the higher the market concentration, and the larger the probability of enterprises withdrawing from the GVC. The coefficients of other control variables are all negative, indicating that the better the enterprise's own situation is, such as the larger the scale, the better the operating condition and the higher the total factor productivity, the more conducive it is to reducing the risk of enterprises exiting the GVC and enhancing the stability of the embedded GVC.

Economic policies play a strong role in regulating market vitality. Both foreign and domestic EPU play an important guiding role in the operation and development of enterprises. However, economic policy is not invariable. The uncertainty of economic policy directly affects the business activities of enterprises and even determines the survival of enterprises. An increase in EPU will have an adverse impact on investment income, product innovation and enterprise management. When economic policy is uncertain, it is more difficult for enterprises to predict future market prospects, the default risk increases, the principal-agent problem deepens, the financing cost and financing difficulty of enterprises also increase, and the investment risk of enterprises increases. To cope with EPU, enterprises spend more funds on maintaining existing operating products, reducing product research and development and improving product quality less. These effects are detrimental to the expansion of enterprises' international market business and increase the risk of enterprises withdrawing from the GVC.

${ }^{1} \mathrm{http}: / /$ www.policyuncertainty.com 
Table 2: Basic regression results

\begin{tabular}{|c|c|c|c|c|}
\hline \multirow{3}{*}{ EPUG } & (1)Inter. & (2)Dom. & (3)Inter. & (4)Dom. \\
\hline & $0.084^{* * * *}$ & & $0.015^{* * \cdots}$ & \\
\hline & $(0.004)$ & & $(0.005)$ & \\
\hline \multirow[t]{2}{*}{ EPUC } & & $0.071^{\text {*****4 }}$ & & $0.064^{* * *}$ \\
\hline & & $(0.004)$ & & $(0.003)$ \\
\hline \multirow[t]{2}{*}{ size } & & & $-0.013^{* * * * *}$ & $-0.006^{* *}$ \\
\hline & & & $(0.001)$ & $(0.001)$ \\
\hline \multirow[t]{2}{*}{$\mathrm{tfp}$} & & & $-0.008^{* * * * * * 1}$ & $-0.018^{* *}$ \\
\hline & & & $(0.001)$ & $(0.001)$ \\
\hline \multirow[t]{2}{*}{ oyxz } & & & -0.001 & $-0.003^{\text {** }}$ \\
\hline & & & $(0.001)$ & $(0.001)$ \\
\hline \multirow[t]{3}{*}{ myfs } & & & $-0.029^{* *}$ & $-0.025^{* *}$ \\
\hline & & & $(0.001)$ & $(0.001)$ \\
\hline & (1)Inter. & (2)Dom. & (3)Inter. & (4)Dom. \\
\hline \multirow[t]{2}{*}{ age } & & & $-0.000^{*}$ & $-0.001^{* *}$ \\
\hline & & & $(0.000)$ & $(0.000)$ \\
\hline \multirow[t]{2}{*}{ finance } & & & 0.002 & $0.002^{* *}$ \\
\hline & & & $(0.002)$ & $(0.001)$ \\
\hline \multirow[t]{2}{*}{$\mathrm{HHI}$} & & & $0.150^{*}$ & $0.509^{* * * *}$ \\
\hline & & & $(0.085)$ & $(0.076)$ \\
\hline \multirow[t]{2}{*}{ Constant } & $-0.170^{* * * *}$ & $-0.104^{* * * * 4}$ & $0.307^{* * * * 1}$ & $0.139^{* * * *}$ \\
\hline & $(0.018)$ & $(0.016)$ & $(0.025)$ & $(0.016)$ \\
\hline Industry effect & Yes & Yes & Yes & Yes \\
\hline Regional effect & Yes & Yes & Yes & Yes \\
\hline Year effect & Yes & Yes & Yes & Yes \\
\hline$N$ & 163,203 & 252,234 & 158,865 & 245,259 \\
\hline$R^{2}$ & 0.003 & 0.002 & 0.086 & 0.012 \\
\hline
\end{tabular}

Notes: Clustering robust standard error in brackets, $* * *$ is $\mathrm{P}<0.01, * *$ is $\mathrm{P}<0.05, *$ is $\mathrm{P}<0.1$. The following table is the same.

\subsection{Robustness test}

In this paper, a robustness test is carried out by changing samples and replacing the measurement methods of key variables.

1. The research sample of this paper includes microenterprises. Microenterprises have many uncertain factors, their ability is too weak to resist risks, and they are prone to frequently enter and exit the market. They also have poor stability, which may lead to overestimation of the impact of EPU. Therefore, this paper deletes the data of microenterprises from the overall sample and repeats the regression. The results are shown in columns (1) and (2) of Table 3. International and domestic EPU still has a significant negative impact on the stability of embedded GVC, indicating that the basic regression result is robust.

2. Key variables may produce different regression results using different measurement methods. First, this paper changes the EPU measurement method and uses the EPU index calculated by Brogaard and detzel (2015). The EPU index is monthly data, so this paper uses the arithmetic average method to obtain the annual 
data and repeat the regression. The results are shown in columns (3) and (4) of Table 3. International and domestic EPU still has a negative and significant impact on the embedded GVC stability of enterprises at the 1\% level. Second, the calculation method of FVAR is replaced by the method of Upward et al. (2013), that is, the FVA comes from the intermediate input of imports or indirect imports. The results are shown in columns (5) and (6) of Table 3, and the regression result is still significantly negative. In conclusion, neither changing the samples nor replacing the measurement method of key variables has a considerable impact on the regression results. International or domestic EPU enhances the probability of enterprises exiting the GVC and reduces the stability of enterprises becoming embedded in the GVC, indicating that the results of basic regression are robust.

Table 3: Robustness test results

\begin{tabular}{|c|c|c|c|c|c|c|}
\hline & \multicolumn{2}{|c|}{ Delete } & \multicolumn{2}{l|}{ Arithmetic mean } & \multicolumn{2}{c|}{ Change FVAR } \\
\hline & $(\mathbf{1})$ & $\mathbf{( 2 )}$ & $\mathbf{( 3 )}$ & $\mathbf{( 4 )}$ & $\mathbf{( 5 )}$ & $\mathbf{( 6 )}$ \\
\hline EPUG & $0.016^{* * *}$ & & $0.020^{* * *}$ & & $0.015^{* * * *}$ & \\
\hline & $(0.005)$ & & $(0.005)$ & & $(0.005)$ & \\
\hline EPUC & & $0.064^{* * *}$ & & $0.087^{* * *}$ & & $0.064^{* * *}$ \\
\hline & & $(0.003)$ & & $(0.004)$ & & $(0.004)$ \\
\hline Constant & $0.305^{* * *}$ & $0.141^{* * *}$ & $0.287^{* * *}$ & $0.033^{*}$ & $0.301^{* * *}$ & $0.134^{* * *}$ \\
\hline & $(0.025)$ & $(0.017)$ & $(0.024)$ & $(0.018)$ & $(0.025)$ & $(0.017)$ \\
\hline Control & Yes & Yes & Yes & Yes & Yes & Yes \\
\hline Industry effect & Yes & Yes & Yes & Yes & Yes & Yes \\
\hline Regional effect & Yes & Yes & Yes & Yes & Yes & Yes \\
\hline Year effect & Yes & Yes & Yes & Yes & Yes & Yes \\
\hline$N$ & 158,736 & 244,840 & 158,865 & 245,259 & 153,728 & 237,402 \\
\hline$R^{2}$ & 0.086 & 0.012 & 0.086 & 0.013 & 0.086 & 0.012 \\
\hline
\end{tabular}

Notes: columns (1),(3),(5) is International EPU and columns (2), (4),(6) is domestic EPU. following table is the same.

\subsection{Endogenous test}

Because economic policy is a macro-policy, the individual behavior of domestic enterprises can hardly affect the economic policies of various countries, so there is almost no reverse causal relationship between the stability of enterprises embedding GVC and the uncertainty of domestic and foreign economic policies. In addition, this paper controls for the fixed effects of industry, region and year in the empirical study and effectively alleviates the endogeneity problems caused by missing variables. In this paper, the endogeneity problems caused by other factors are alleviated by the following three methods:

1. The core variable of economic policy uncertainty is delayed by one period, and the results are shown in columns (1) and (2) of Table 4.

2. All explanatory variables are delayed by one period, and the results are shown in columns (3) and (4) of Table 4. 
3. Adding instrumental variables: This paper selects the average value of the economic policy uncertainty index outside the country (region) as the instrumental variable of the economic policy uncertainty index in the country (region). The results are shown in columns (5) and (6) of Table 4.

From Table 4, it can be seen that the endogenous test results are consistent with the basic regression results. This shows that increasing domestic and foreign EPU can increase the probability of enterprises exiting the GVC and reduce the stability of enterprises embedded in the GVC.

Table 4: Endogenous test results

\begin{tabular}{|c|c|c|c|c|c|c|}
\hline & \multicolumn{2}{|c|}{$\begin{array}{c}\text { Core explanatory } \\
\text { variable lag }\end{array}$} & \multicolumn{2}{c|}{$\begin{array}{c}\text { All explanatory } \\
\text { variables lag }\end{array}$} & \multicolumn{2}{c|}{$\begin{array}{c}\text { Instrumental } \\
\text { variable }\end{array}$} \\
\hline & $\mathbf{( 1 )}$ & $\mathbf{( 2 )}$ & $\mathbf{( 3 )}$ & $\mathbf{( 4 )}$ & $\mathbf{( 5 )}$ & $(\mathbf{6})$ \\
\hline EPUG & $0.011^{* *}$ & & $0.010^{* *}$ & & $0.209^{* * * *}$ & \\
\hline & $(0.006)$ & & $(0.006)$ & & $(0.006)$ & \\
\hline EPUC & & $0.029^{* * *}$ & & $0.030^{* * *}$ & & $0.185^{* * *}$ \\
\hline & & $(0.004)$ & & $(0.004)$ & & $(0.004)$ \\
\hline Constant & $0.158^{* * *}$ & $0.045^{* * *}$ & $0.122^{* * *}$ & 0.017 & $0.345^{* * *}$ & $0.221^{* * *}$ \\
\hline & $(0.026)$ & $(0.017)$ & $(0.026)$ & $(0.017)$ & $(0.069)$ & $(0.055)$ \\
\hline Control & Yes & Yes & Yes & Yes & Yes & Yes \\
\hline Industry effect & Yes & Yes & Yes & Yes & Yes & Yes \\
\hline Regional effect & Yes & Yes & Yes & Yes & Yes & Yes \\
\hline Year effect & Yes & Yes & Yes & Yes & Yes & Yes \\
\hline$N$ & 102,140 & 154,641 & 102,911 & 155,794 & 158,866 & 245,260 \\
\hline$R^{2}$ & 0.024 & 0.009 & 0.016 & 0.007 & 0.009 & 0.008 \\
\hline
\end{tabular}

\subsection{Heterogeneity test}

According to the results of the previous basic regression, different enterprises' own conditions impact the stability of GVC embedding. Therefore, this paper distinguishes the scale, type and product category of GVC embedding by enterprises and conducts a heterogeneity test to explore the influence of EPU on the stability of GVC embedding by different enterprises.

1. Heterogeneity of enterprise scale. According to the division standard of the National Bureau of Statistics, the enterprise samples are divided into large, medium, small and micro enterprises according to the corresponding standards of employees and operating income. Table 5, columns (1), (3), (5) and (7) show the influence of international economic policy uncertainty on the stability of China's large, medium, small and micro enterprises embedded in the GVC, and columns (2), (4), (6) and (8) show the influence of China's economic policy uncertainty on China's large, medium, small and micro enterprises. The results show that international EPU has a significant impact on only small enterprises in China, which reduces the stability of small enterprises embedded in the GVC. Domestic economic policy uncertainty also has a significant impact on enterprises of all sizes, and domestic EPU reduces the stability of domestic enterprises embedded in the GVC. Domestic policy 
changes have a more direct impact on Chinese enterprises than do international policy changes, which affects enterprises' investment, production and stable development in the international market and reduces their stability of embedding GVC. International EPU has a relatively weak impact on domestic enterprises and China's large- and medium-sized enterprises due to their large scale. Its development is stable, and its impact is relatively small. Because of the extremely weak development stability of microenterprises, the impact is not obvious. Although small enterprises are small in scale, they have occupied a certain development position in the market. However, they are unstable compared with large- and medium-sized enterprises, so they are more vulnerable to the impact of policy uncertainty.

Table 5: Heterogeneity test of enterprise scale

\begin{tabular}{|c|c|c|c|c|c|c|c|c|}
\hline & \multicolumn{2}{|c|}{$\begin{array}{c}\text { Large } \\
\text { enterprises }\end{array}$} & \multicolumn{2}{c|}{$\begin{array}{c}\text { Medium } \\
\text { enterprises }\end{array}$} & \multicolumn{2}{c|}{$\begin{array}{c}\text { Small } \\
\text { enterprises }\end{array}$} & \multicolumn{2}{c|}{$\begin{array}{c}\text { Micro } \\
\text { enterprises }\end{array}$} \\
\cline { 2 - 9 } & $\mathbf{( 1 )}$ & $\mathbf{( 2 )}$ & $\mathbf{( 3 )}$ & $\mathbf{( 4 )}$ & $\mathbf{( 5 )}$ & $\mathbf{( 6 )}$ & $\mathbf{( 7 )}$ & $\mathbf{( 8 )}$ \\
\hline EPUG & 0.031 & & 0.005 & & $0.016^{* *}$ & & 0.001 & \\
\hline & $(0.025)$ & & $(0.010)$ & & $(0.007)$ & & $(0.046)$ & \\
\hline EPUC & & $0.124^{* * *}$ & & $0.067^{* * *}$ & & $0.052^{* * *}$ & & $0.084^{* * *}$ \\
\hline & & $(0.014)$ & & $(0.007)$ & & $(0.004)$ & & $(0.032)$ \\
\hline Constant & 0.122 & $-0.278^{* * * *}$ & $0.203^{* * *}$ & 0.013 & $0.287^{* * *}$ & $0.203^{* * *}$ & $0.586^{* * *}$ & $0.249^{*}$ \\
\hline & $(0.119)$ & $(0.080)$ & $(0.048)$ & $(0.034)$ & $(0.030)$ & $(0.021)$ & $(0.213)$ & $(0.146)$ \\
\hline Control & Yes & Yes & Yes & Yes & Yes & Yes & Yes & Yes \\
\hline $\begin{array}{c}\text { Industry } \\
\text { effect }\end{array}$ & Yes & Yes & Yes & Yes & Yes & Yes & Yes & Yes \\
\hline $\begin{array}{c}\text { Regional } \\
\text { effect }\end{array}$ & Yes & Yes & Yes & Yes & Yes & Yes & Yes & Yes \\
\hline $\begin{array}{c}\text { Year } \\
\text { effect }\end{array}$ & Yes & Yes & Yes & Yes & Yes & Yes & Yes & Yes \\
\hline$N$ & 7,525 & 11,605 & 40,213 & 60,906 & 108,340 & 168,682 & 2,782 & 4,063 \\
\hline$R^{2}$ & 0.101 & 0.038 & 0.078 & 0.017 & 0.088 & 0.011 & 0.166 & 0.043 \\
\hline
\end{tabular}

2. Heterogeneity of enterprise types. This paper further divides enterprises into three types, namely, state-owned enterprises, private enterprises and foreign invested enterprises, and the results are shown in Table 6. International EPU has no significant impact on state-owned enterprises but significantly reduces the stability of private enterprises and foreign invested enterprises embedded in the GVC. Domestic EPU does not have a significant impact on foreign invested enterprises but significantly reduces the stability of state-owned enterprises and private enterprises embedded in the GVC. Foreign-funded enterprises rely on the inherent natural links and advantages between enterprises and multinational companies and are more closely connected with the international market, so they will be more affected by international economic policies than domestic economic policies. Private enterprises are equally affected by domestic and foreign economic policies, both of which can affect the stability of their embedding in the GVC. State-owned 
enterprises are relatively more susceptible to the influence of domestic economic policies.

3. The heterogeneity of enterprises embedding the GVC in different product forms. This paper divides enterprises into those involved in the import and export of intermediate products and those not involved in the import and export of intermediate products according to whether they embed the GVC in the form of intermediate products. The regression results are shown in Table 7. Regardless of international economic policy or domestic economic policy, EPU increases the probability of enterprises involved in the import and export of intermediate products withdrawing from the GVC and reduces the stability of enterprises embedded in the GVC. For enterprises that do not involve intermediate goods, an increase in domestic EPU reduces the stability of enterprise embedding in the GVC, while the influence of international EPU is not significant. Enterprises involved in the import and export of intermediate products are not only affected by their own business conditions but also involved in the import and export of upstream and downstream products in the international market because they are involved in the import and export of intermediate products, and they are more significantly affected by the EPU.

Table 6: Heterogeneity test of enterprise types

\begin{tabular}{|c|c|c|c|c|c|c|}
\hline & \multicolumn{2}{|c|}{$\begin{array}{c}\text { State-owned } \\
\text { enterprises }\end{array}$} & \multicolumn{2}{l|}{ Private enterprises } & \multicolumn{2}{c|}{$\begin{array}{c}\text { Foreign invested } \\
\text { enterprises }\end{array}$} \\
\cline { 2 - 7 } & $\mathbf{( 1 )}$ & $\mathbf{( 2 )}$ & $\mathbf{( 3 )}$ & $\mathbf{( 4 )}$ & $\mathbf{( 5 )}$ & $\mathbf{( 6 )}$ \\
\hline EPUG & 0.023 & & $0.018^{* * *}$ & & $0.017^{* *}$ & \\
\hline & $(0.016)$ & & $(0.007)$ & & $(0.009)$ & \\
\hline EPUC & & $0.148^{* * *}$ & & $0.055^{* * *}$ & & -0.003 \\
\hline & & $(0.009)$ & & $(0.005)$ & & $(0.006)$ \\
\hline Constant & $0.242^{* * *}$ & $-0.261^{* * *}$ & $0.306^{* * *}$ & $0.164^{* * *}$ & $0.331^{* * *}$ & $0.492^{* * *}$ \\
\hline & $(0.074)$ & $(0.044)$ & $(0.033)$ & $(0.023)$ & $(0.041)$ & $(0.027)$ \\
\hline Control & Yes & Yes & Yes & Yes & Yes & Yes \\
\hline Industry effect & Yes & Yes & Yes & Yes & Yes & Yes \\
\hline Regional effect & Yes & Yes & Yes & Yes & Yes & Yes \\
\hline Year effect & Yes & Yes & Yes & Yes & Yes & Yes \\
\hline$N$ & 17,453 & 29,449 & 85,541 & 130,355 & 55,870 & 85,451 \\
\hline$R^{2}$ & 0.072 & 0.019 & 0.094 & 0.010 & 0.082 & 0.021 \\
\hline
\end{tabular}


Table 7: Heterogeneity test of enterprises embedding GVC in different product forms

\begin{tabular}{|c|c|c|c|c|}
\hline & \multicolumn{2}{|c|}{$\begin{array}{c}\text { Involving intermediate } \\
\text { products }\end{array}$} & $\begin{array}{c}\text { Intermediate products are } \\
\text { not involved }\end{array}$ \\
\hline & $\mathbf{( 1 )}$ & $\mathbf{( 2 )}$ & $\mathbf{( 3 )}$ & $\mathbf{( 4 )}$ \\
\hline EPUG & $0.034^{* * *}$ & & 0.003 & \\
\hline & $(0.008)$ & & $(0.008)$ & \\
\hline EPUC & & $0.026^{* * *}$ & & $0.089^{* * *}$ \\
\hline & & $(0.005)$ & & $(0.005)$ \\
\hline Constant & $0.193^{* * *}$ & $0.236^{* * *}$ & $0.397^{* * *}$ & $0.067^{* * *}$ \\
\hline & $(0.035)$ & $(0.023)$ & $(0.035)$ & $(0.024)$ \\
\hline Control & Yes & Yes & Yes & Yes \\
\hline Industry effect & Yes & Yes & Yes & Yes \\
\hline Regional effect & Yes & Yes & Yes & Yes \\
\hline Year effect & Yes & Yes & Yes & Yes \\
\hline$N$ & 83,859 & 115,965 & 75,005 & 129,292 \\
\hline$R^{2}$ & 0.077 & 0.011 & 0.099 & 0.014 \\
\hline
\end{tabular}

\subsection{Influence mechanism test}

This paper further explores the influence mechanism of economic policy uncertainty on the stability of enterprises embedding the GVC and tests it.

Many scholars believe that an increase in economic policy uncertainty will hinder enterprises from carrying out innovation activities (Bhattacharya et al., 2017). EPU will increase the various risks faced by enterprises, resulting in insufficient innovation funds, declining R\&D enthusiasm and other related problems, thereby inhibiting enterprise innovation. When the innovation ability of enterprises is restrained, the competitiveness of enterprises in the international market is reduced, and the substitutability of enterprises' products will increase, thereby enhancing the probability of enterprises exiting the GVC and reducing the stability of enterprises embedding the GVC.

Based on the above research, this paper finds that EPU reduces the stability of GVC embedding by reducing the innovation ability of enterprises.

Equations (7)-(9) are constructed to test the influence mechanism. EPUX ${ }_{i t}$ indicates the EPU, which is expressed by $E P U C_{i t}$ and $E P U G_{i t} ; N E W_{i j k t}$ indicates the innovation ability of an enterprise, which is measured as the logarithm of the output value of new products of enterprises.

$$
\begin{gathered}
N E W_{i j k t}=\beta_{0}+\beta_{1} * E P U X_{i t}+\gamma * X_{i j k t}+v_{t}+v_{j}+v_{k}+\varepsilon_{i j k t} \\
\operatorname{clog} \log \left(1-h_{i t}\right)=\beta_{2}+\beta_{3} * N E W_{i j k t}+\gamma * X_{i j k t}+v_{t}+v_{j}+v_{k}+\varepsilon_{i j k t}{ }^{2} \\
\operatorname{clog} \log \left(1-h_{i t}\right)=\beta_{4}+\beta_{5} * E P U X_{i t}+\beta_{6} * N E W_{i j k t}+\gamma * X_{i j k t}+v_{t}+v_{j}+v_{k}+\varepsilon_{i j k t}
\end{gathered}
$$


From columns (1) and (2) of Table 8, we can see that domestic and international EPU have a significant negative influence on the innovation ability of enterprises; column (3) shows that the innovation ability of enterprises can significantly improve the stability of GVC embedding. However, when enterprise innovation and EPU are added to the regression as explanatory variables, as shown in columns (4) and (5), the coefficient of domestic EPU remains significantly negative, while the coefficient of international EPU is significantly positive. Therefore, an increase in domestic EPU will reduce the innovation ability of enterprises, thus improving the probability of enterprises exiting the GVC and reducing the stability of enterprises embedding GVC, but enterprise innovation cannot be used as the influence channel of international EPU on the stability of enterprises embedding GVC.

Table 8: Influence mechanism test results

\begin{tabular}{|c|c|c|c|c|c|}
\hline & $(\mathbf{1})$ & $\mathbf{( 2 )}$ & $\mathbf{( 3 )}$ & $\mathbf{( 4 )}$ & $\mathbf{( 5 )}$ \\
\hline EPUC & $-1.785^{* * *}$ & & & $-0.456^{* * *}$ & \\
\hline & $(0.060)$ & & & $(0.008)$ & \\
\hline EPUG & & $-1.222^{* * *}$ & & & $0.022^{\text {**** }}$ \\
\hline & & $(0.040)$ & & & $(0.005)$ \\
\hline NEW & & & $-0.001^{* * *}$ & $-0.002^{* * *}$ & $-0.001^{* * *}$ \\
\hline & & & $(0.000)$ & $(0.000)$ & $(0.000)$ \\
\hline Constant & $5.023^{* * * *}$ & $2.647^{* * *}$ & $0.388^{* * *}$ & $2.331^{* * *}$ & $0.292^{* * *}$ \\
\hline & $(0.261)$ & $(0.185)$ & $(0.007)$ & $(0.034)$ & $(0.024)$ \\
\hline Control & Yes & Yes & Yes & Yes & Yes \\
\hline Industry effect & Yes & Yes & Yes & Yes & Yes \\
\hline Regional effect & Yes & Yes & Yes & Yes & Yes \\
\hline Year effect & Yes & Yes & Yes & Yes & Yes \\
\hline$N$ & 187,276 & 132,034 & 187,276 & 187,276 & 132,034 \\
\hline$R^{2}$ & 0.127 & 0.136 & 0.011 & 0.029 & 0.013 \\
\hline
\end{tabular}

Notes: The explanatory variables in columns (1) and (2) are the innovation ability of enterprises; the explanatory variables in columns (3) - (5) are the stability of GVC embedding.

\section{Conclusion}

By matching the microdata of the China Industrial Enterprise Database and Customs Database from 2000 to 2007, this paper explores the influence of domestic and international EPU on the stability of the GVC chain of Chinese enterprises and draws the following conclusions.

First, the average duration of GVC embedding in Chinese enterprises is short, and its stability is low. Eastern enterprises, processing trade enterprises, foreign-funded enterprises and enterprises involved in the import and export of intermediate products have been embedded into GVCs for a long time and are relatively stable. The trends of the EPU index in China and the world are basically the same and fluctuate greatly; both rose sharply in 2001. Second, domestic and international EPU increase the probability of enterprises exiting the GVC and reduce the stability 
of enterprises embedded in the GVC. Domestic EPU mainly reduces the stability of embedding in the GVC by inhibiting the innovation ability of enterprises. Third, international EPU reduces the stability of private enterprises, foreign-funded enterprises, small enterprises and enterprises involved in the import and export of intermediate products embedded in the GVC. Domestic EPU reduces the stability of state-owned enterprises, private enterprises, large, medium and small enterprises and enterprises involved in the import and export of intermediate products embedded in the GVC.

Based on the research results above, this paper proposes the following suggestions for enhancing the stability of enterprises embedded in the GVC.

First, enterprises should pay close attention to the changing trend of economic policies, judge the trend of policies and laws, adjust the industrial direction and internal resource allocation in time, and take measures to address economic policy changes in advance. Second, enterprises should make good use of their own resources, innovate and improve their core products, perform product innovation constantly, and improve the market competitiveness of products. Third, enterprises should strengthen cooperation both domestically and internationally. Under the globalization background of domestic and foreign market linkages, upstream and downstream industry linkages, and international trade and investment linkages, enterprises should efficiently integrate and utilize global intellectual capital and scientific and technological resources, strengthen international cooperation and actively integrate into global production networks. Based on the above, the stability of enterprises embedded in the GVC should be continuously improved to provide strong guarantees and power for the sustainable development of China and even the world.

\section{References}

[1] Alesina, A. and Perotti, R. (1996). Income distribution, political instability, and investment." European Economic Review,40(6),pp.1203-1228.

[2] Alfaro, I., Bloom, N. and Lin, X. (2018). The finance uncertainty multiplier. NBER.

[3] Bakas, D. and Triantafyllou, A. (2018). The impact of uncertainty shocks on the volatility of commodity prices. Journal of International Money and Finance, 87(10),pp.96-111.

[4] Baker, S.R., Bloom, N. and Davis, S.J. (2016). Measuring economic policy uncertainty. The Quarterly Journal of Economics,131(4),pp.1593-1636.

[5] Basu, S. and Bundick, B. (2017). Uncertainty shocks in a model of effective demand. Econometrica, 85(3),pp.937-958.

[6] Besedes, T. and Prusa, T.J.(2006).Product differentiation and duration of US import trade. Journal of International Economics, 70(2),pp.339-358.

[7] Bhattacharya, U., Hsu, P.H., Tian, X. and Xu, Y. (2017). What affects innovation more: Policy or policy uncertainty? Journal of Financial and Quantitative Analysis, 52(5),pp.1869-1901. 
[8] Bridgman, B. (2012). The rise of vertical specialization trade. Journal of International Economics, 86,pp.133-140.

[9] Brogaard, J. and Detzel, A. (2015). The asset-pricing implications of government economic policy uncertainty. Management

Science,61(1),pp.3-18.

[10] Caldara, D., Iacoviello, M., Molligo, P., Prestipino and Raffo,A. (2020).The economic effects of trade policy uncertainty. Journal of Monetary Economics, 109,pp.38-59.

[11] Carballo, J., Handley, K. and Limão, N. (2018). Economic and policy uncertainty: Export dynamics and the value of agreements. NBER.

[12] Chen, Y.B., Li, Y. and Zhou, S.M. (2012).The duration of firm-destination export relationships: evidence from China. Economic Research Journal, 47(7),pp.48-61.

[13] Christensen, I. and Dib, A. (2008). The financial accelerator in an estimated new keynesian model. Review of Economic Dynamics,11(1),pp.155-178.

[14] Daniels, J.P. and Ruhr, M.V.D. (2014). Transportation costs and US manufacturing FDI. Review of International Economics,22(2),pp.299-309.

[15] Esteve-Pérez, S., Requena-Silvente, F. and Pallardo-lopez, J.V. (2013).The duration of firm-destination export relationships: Evidence from Spain, 19972006. Economic Inquiry,51(1),pp.159-180.

[16] Greenland, A., Ion, M. and Lopresti, J. (2019). Exports, investment and policy uncertainty. Canadian Journal of Economics,52(3),pp.1248-1288.

[17] Gulen, H. and Ion, M. (2016). Policy uncertainty and corporate investment. The Review of Financial Studies, 29(3),pp.523-564.

[18] Handley, K. and Limão, N. (2017). Policy uncertainty, trade, and welfare: Theory and evidence for China and the United States. American Economic Review, 107(9),pp.2731-2783.

[19] Haroon, M. (2018). Does uncertainty affect real activity? Evidence from statelevel data. Economics Letters, 167,pp.127-130.

[20] Hou, X.H., Wang, T.Y. and Ma, C.Y. (2021). Economic policy uncertainty and corporate fraud. Economic Analysis and Policy, 71(2),pp.97-110.

[21] Hummels, D., Ishii, J. and Yi, K.M. (2011). The nature and growth of vertical specialization in world trade. Journal of International Economics,54(1),pp.7596.

[22] Humphrey, J. and Schmitz, H. (2002). Developing country firms in the world economy: Governance and upgrading in global value chains. INEF Report,61,pp.25-27.

[23] Julio, B. and Yook, Y. (2012). Political uncertainty and corporate investment cycles. Journal of Finance, 67(1),pp.45-83.

[24] Koopman, R., Powers, W., Wang, Z. and Wei, S.J. (2010). Give credit where credit is due: Tracing value added in global production chains. NBER.

[25] Koopman, R., Wang, Z. and Wei, S.J. (2012). Estimating domestic content in exports when processing trade is pervasive. Journal of Development Economics,99(1),pp.178-189. 
[26] Leduc, S. and Liu, Z. (2016). Uncertainty shocks are aggregate demand shocks. Journal of Monetary Economics, 82(2),pp.20-35.

[27] Lv, Y., Liu, Z.Y. and Lv, Y.L. (2017). The duration of GVC embedment and decisive factors: evidence from China. The Journal of Quantitative \& Technical Economics,34,pp.37-53.

[28] Manova, K., and Yu, Z.H. (2012). Firms and credit constraints along the global value chain: Processing trade in China. NBER.

[29] Martin, R. and Sunley. P. (2015). On the notion of regional economic resilience: Conceptualization and explanation. Journal of Economic Geography,15(1),pp.1-42.

[30] Nguyen, Q., Kim, T. and Papanastassiou, M. (2018). Policy uncertainty, derivatives use, and firm-level FDI. Journal of International Business Studies, 49,pp.96-126.

[31] Nitsch, V. (2009). Die another day: duration in German import trade. Review of World Economics, 145,pp.133-154.

[32] Olley, G.S. and Pakes, A., (1996). The dynamics of productivity in the telecommunications equipment industry. Econometrica, 64(6),pp.1263-1297.

[33] Pastor, L. and Veronesi, P. (2012). Uncertainty about government policy and stock price. Journal of Finance,53(4),pp.753-772.

[34] Phan, H.V., Nguyen, N.H., Nguyen, H.T. and Hegde, S. (2019). Policy uncertainty and firm cash holdings. Journal of Business Research,95(2),pp.7182.

[35] Sun, J.Z., Lee, H.J. and Yang, J. (2021).The Impact of the COVID-19 pandemic on the global value chain of the manufacturing Industry.Sustainability, 13,12370.

[36] Upward, R., Wang, Z. and Zheng, J. (2013). Weighing China' s export basket: The domestic content and technology intensity of Chinese exports. Journal of comparative economics,41(2),pp.527-543.

[37] Wang, H., Shen, H.Y., Tang, X.Y., Wu, Z.F. and Ma, S.M. (2021). Trade policy uncertainty and firm risk taking. Economic Analysis and Policy,70,pp.351-364.

[38] Yagi, M. and Managi, S. (2021). Global supply constraints from the 2008 and COVID-19 crises. Economic Analysis and Policy, 69,pp.514-528.

[39] Zheng, S.F., Xie, H.Q. and Liu, D.D. (2020). A study of economic policy uncertainty on global value chain. Journal of International Trade, 4,pp.69-85. 